\title{
Visualizing the Hyperaccumulation of Metals in Fucus gardneri From Howe Sound, British Columbia, Canada, Using Synchrotron X-ray Fluorescence Mapping
}

\author{
Lisa L. Van Loon ${ }^{1,2^{*}}$, Neil R. Banerjee ${ }^{2}$, Diane Mitchell ${ }^{3}$, and Colin Dunn ${ }^{4}$ \\ 1. LISA CAN Analytical Solutions Inc., Saskatoon, SK, Canada. \\ 2. Department of Earth Sciences, Western University, London, ON, Canada. \\ 3. Britannia Mine Museum, Britannia Beach, BC, Canada. \\ 4. Colin Dunn Consulting, North Saanich, BC, Canada. \\ Corresponding author: lisavanloon@gmail.com
}

Once known as the largest single point discharge of heavy metal pollution into a marine environment, the remediation of the former Britannia Mine, located between Vancouver and Squamish, BC, Canada, has been instrumental in regenerating Howe Sound's ecosystem and the Britannia Mountains watershed. After closure in 1974, drainage from the abandoned mine tunnels used to seep down the mountainside into Howe Sound. This fjord-like inlet has prolific growth of the rockweed species Fucus gardneri lining the intertidal zone. In the early 1990's for a distance of more than $1 \mathrm{~km}$ on either side of the drainage from the mine into Howe Sound there was no rockweed growth. Where it first appeared, it was stunted, and samples yielded up to $1000 \mathrm{ppm} \mathrm{Cu}$ dry weight [1]. This is >50 times background levels, attesting to the high degree of metal accumulation that the seaweed can withstand.

A 2015 re-survey of the same areas by Dunn [2,3] has shown drastic decrease in metal accumulations in rockweed and a return to colonization near the drainage from the mine. However, rockweed samples still show enrichment in $\mathrm{Cu}$ and $\mathrm{Zn}$ close to Britannia Beach that is likely derived either from the mine or natural levels from the mineralized bedrock. A close correspondence between the metal content of rockweed and that of seawater is expected because algae are non-vascular plants. It is not yet well understood how rockweed hyperaccumulates metals like $\mathrm{Cu}$ and $\mathrm{Zn}$. Synchrotron $\mathrm{X}$-ray fluorescence (SR-XRF) analysis images the distribution of elements in the holdfast and blade. This information will help elucidate the mechanism of element hyperaccumulation by the rockweed species Fucus gardneri.

Experimental: In August 2016 Fucus gardneri samples were collected at 7 locations north and south of the Britannia Mine, near the locations sampled in the 2015 survey [2,3] but accessible from the highway. The samples collected were visibly representative of the rockweed growing at each location. The samples were dried and kept at $-80^{\circ} \mathrm{C}$ prior to $\mathrm{SR}-\mathrm{XRF}$ analysis.

The samples were analyzed by SR-XRF at the F3 beamline at the Cornell High Energy Synchrotron Source (CHESS) in Ithaca, NY to create 2D trace element maps that reveal spatial and structural associations. The incident X-ray energy was set to $16.2 \mathrm{keV}$. A 4-element SDD Vortex detector with a Quantum express processor was used to measure the XRF signal. SR-XRF mapping was done by rastering across the samples with a beam spot size of $100 \mu \mathrm{m}$ x $100 \mu \mathrm{m}$ in both directions using a dwell time of $100 \mathrm{msec}$. High resolution mapping of select regions was then performed under similar conditions with a beam spot size of $20 \mu \mathrm{m}$ x $20 \mu \mathrm{m}$. The distance between the sample and detector was kept constant for all samples. Data analysis was done using pyMCA 5.3.1 [4].

Results: Synchrotron XRF mapping analysis conducted on samples collected near Britannia Beach shows the distribution of elements within the rockweed, delineating micron scale accumulations and 
reveals relationships between plant physiology and metal hotspots. An example is shown of a sample collected at a location expected to have high $\mathrm{Cu}$ and $\mathrm{Zn}$ concentrations (Fig. 1 \& 2). $\mathrm{Cu}$ and $\mathrm{Zn}$ are primarily concentrated in nodules. $\mathrm{Zn}$ is observed in the holdfast while $\mathrm{Cu}$ is not. $\mathrm{Ni}$ is distributed throughout the veins and blades. Further work is ongoing to better understand differences in these element distributions by Fucus gardneri.

\section{References:}

[1] C.E. Dunn, J.B. Percival, G.E.M. Hall, \& A. Mudroch, (1992) in "Proceedings of the Howe Sound Environmental Science Workshop”, ed. C.D. Levings, R.B. Turner \& B. Ricketts, (Can. Tech. Rept. Fish. Aquatic Sci., No. 1879) p. 89-100.

[2] C.E. Dunn \& R. McCaffrey, EXPLORE 176 (2017), p. 13-20.

[3] C.E. Dunn \& R. McCaffrey, EXPLORE 178 (2018), p. 1-12.

[4] V. Solé, E. Papillon, M. Cotte, P. Walter, \& J. Susini, Spectrochim. Acta Part B 62 (2007), p. 63-68. [5] We acknowledge funding from NSERC and the CGF. Research described in this paper was performed at the Cornell High Energy Synchrotron Source (CHESS). CHESS is supported by the NSF under award DMR-1332208. We thank A. Woll, R. Huang, and L. Smieska for their support in conducting the experiments and T. Flynn and K. Rozon for their assistance with data collection.
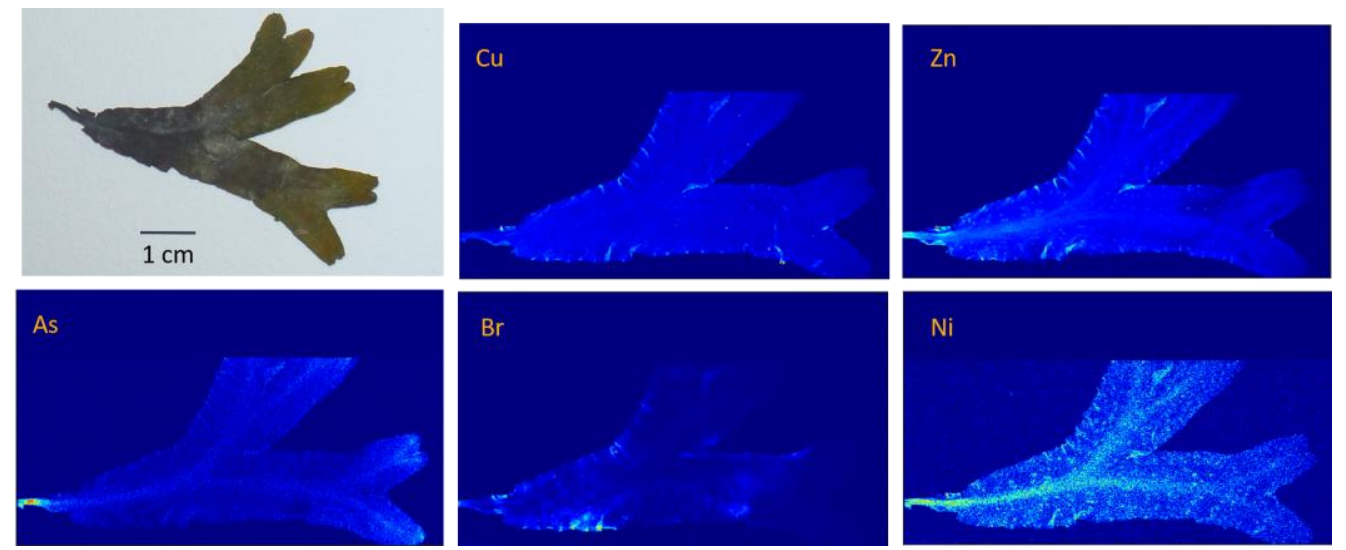

Figure 1. Example of a rockweed sample photograph and $100 \mu \mathrm{m}$ resolution 2D SR-XRF Cu, Zn, As, $\mathrm{Br}$, and $\mathrm{Ni}$ single-element maps. $\mathrm{Cu}$ and $\mathrm{Zn}$ appear to be co-located. As is observed in the holdfast. $\mathrm{Br}$ does not appear to be associated with features in the plant. Ni appears to be distributed throughout the blade and veins.
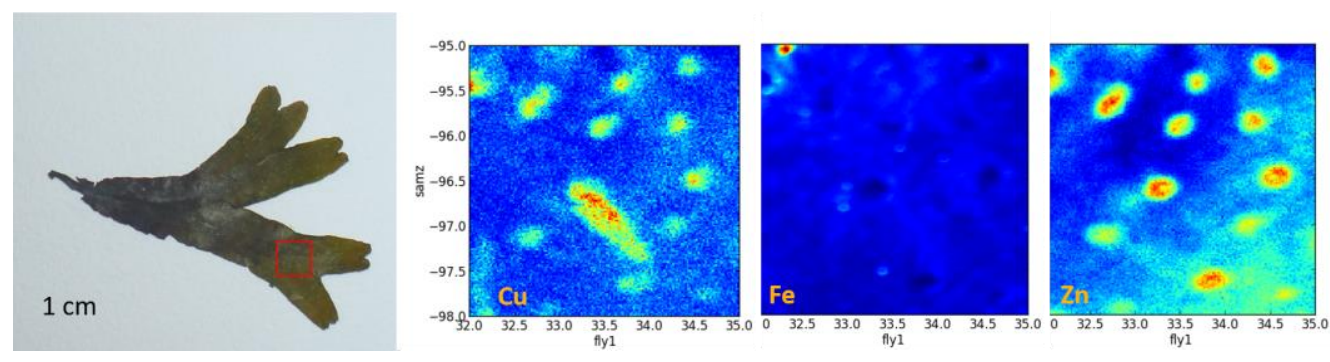

Figure 2. $20 \mu \mathrm{m}$ resolution element maps for $\mathrm{Cu}, \mathrm{Fe}$, and $\mathrm{Zn}$ from a location near the tip of the rockweed (red square). $\mathrm{Cu}$ and $\mathrm{Zn}$ appear to be co-located in nodules. Iron distribution is not associated with $\mathrm{Cu}$ or $\mathrm{Zn}$. 